\title{
Toxic potency-adjusted control of air pollution for solid fuel combustion
}

\author{
Di Wu', ${ }^{1,6}$ Haotian Zheng $\circledast^{2,3,6}$, Qing Li $\circledast^{1 凶}$, Ling Jin $\oplus^{4,5}$, Rui Lyu', Xiang Ding', Yaoqiang Huo', \\ Bin Zhao' ${ }^{2}$, Jingkun Jiang ${ }^{2}$, Jianmin Chen ${ }^{1}{ }^{1}$, Xiangdong Li $\oplus^{4 凶}$ and Shuxiao Wang $\oplus^{2,3 凶}$
}

\begin{abstract}
The combustion of solid fuels, including coal and biomass, is a main anthropogenic source of atmospheric particulate matter (PM). The hidden costs have been underestimated due to lack of consideration of the toxicity of PM. Here we report the unequal toxicity of inhalable PM emitted from energy use in the residential sector and coal-fired power plants (CFPPs). The incomplete burning of solid fuels in household stoves generates much higher concentrations of carbonaceous matter, resulting in more than one order of magnitude greater toxicity than that from CFPPs. When compared with CFPPs, the residential sector consumed only a tenth of solid fuels in mainland China in 2017, but it contributed about 200-fold higher of the population-weighted toxic potency-adjusted $\mathrm{PM}_{2.5}$ exposure risk. We suggest that $\mathrm{PM}_{2.5}$-related toxicity should be considered when making air pollution emission control strategies, and incomplete combustion sources should receive more policy attention to reduce exposure risks.
\end{abstract}

T he combustion of solid fuels has been recognized as the main anthropogenic emission source of particulate matter (PM) that elicits adverse effects on air quality and human health ${ }^{1-4}$. Solid fuels, including coal and biomass, have been widely used for direct energy usage in industrial and residential sectors worldwide ${ }^{5,6}$. As one of the largest consumers of solid fuels, the industrial sector and particularly coal-fired power plants (CFPPs) have received far more attention. PM emissions from CFPPs has greatly decreased in the past few decades in many regions due to phasing out old units, the upgraded emission control technology and strengthening policies enforcement ${ }^{7-9}$. In contrast, the residential sector (including household coal and biomass combustion), as the largest source category of global $\mathrm{PM}_{2.5}$ emissions ${ }^{10,11}$, has been neglected for a long time. Residential solid fuel combustion has caused severe air pollution $^{12,13}$, which has contributed to $31 \%$ to the total premature deaths worldwide and can be even worse in developing countries ${ }^{4,14-17}$.

Toxic potency (the relative concentrations of different chemicals or particulate samples to reach the same level of effect on a given biological endpoint) of source-specific PM per unit mass is an important metric along with mass emission in weighing the exposure risks between emission sources ${ }^{18}$. $\mathrm{PM}_{2.5}$ (PM with an aerodynamic diameter less than $2.5 \mu \mathrm{m}$ ) emitted from industrial boilers and residential stoves varies widely owing to the large discrepancies in real-world combustion practices and after-treatment control levels ${ }^{19-22}$. The PM-related toxic potency, which is shaped by multiple combinations of chemical compositions, may be disparate between the residential sector and CFPPs. The harmful effects resulting from solid fuel combustion have not been fully revealed and are overlooked, especially in the residential sector, without considering aerosol-related toxicity. Substantial knowledge gaps exist relating to how mixtures of chemical constituents, particularly toxic components contained in PM, trigger the overall toxicity ${ }^{23}$. The lack of PM-related toxicity data from real-world combustion limits the current understanding of PM exposure and the devising of air pollution control strategies.

This study proposes toxic potency-adjusted control of air pollution via considering toxicities of source-oriented PM, taking solid fuel combustion in the residential and power plant sectors as an example. The unequal toxicities, including estimations of oxidative stress and cytotoxicity of PM, are revealed through field studies and laboratory analysis. Field measurements of residential combustion are conducted in northern and southern China, while field studies of typical units of CFPPs are conducted in northern and eastern China. The quantitative assessment of PM toxicities, based on the developed air benefit and cost and attainment assessment system (ABaCAS) emission inventory and the weather research and forecasting model-community multiscale air quality (WRF-CMAQ) model, provides further insight into revealing hidden risks from source-oriented PM and devising air pollution emission control strategies. Field measurements and analytical approaches are detailed in Methods and Supplementary Note.

\section{Results and discussion}

Real-world $\mathbf{P M}_{2.5}$ emission profiles. The emission factors (EFs) (the quantity of pollutants released to the ambient air per unit of fuel combusted) of $\mathrm{PM}_{2.5}$ from household combustion are approximately 264 to 324 times higher than those from CFPPs that meet the strictest ultralow emission (ULE) standards in China (Fig. 1a). The $\mathrm{PM}_{2.5}$ EFs for household coal combustion were estimated with weighting factors for coal consumption (Supplementary Note 7). The observed $\mathrm{PM}_{2.5}$ EFs from residential combustion are consistent with those reported in previous studies ${ }^{19220,24,25}$, including the $\mathrm{PM}_{2.5}$ EFs obtained from nationwide field emission measurements conducted in rural China recently ${ }^{26}$. Additionally, the obtained $\mathrm{PM}_{25}$ EFs for CFPPs are consistent with those reported in continuous emissions monitoring systems (the real-time measurements of PM

'Department of Environmental Science and Engineering, Shanghai Key Laboratory of Atmospheric Particle Pollution and Prevention, Fudan University, Shanghai, China. ${ }^{2}$ State Key Joint Laboratory of Environment Simulation and Pollution Control, School of Environment, Tsinghua University, Beijing, China. ${ }^{3}$ State Environmental Protection Key Laboratory of Sources and Control of Air Pollution Complex, Beijing, China. ${ }^{4}$ Department of Civil and Environmental Engineering, The Hong Kong Polytechnic University, Hong Kong, China. ${ }^{5}$ Department of Health Technology and Informatics, The Hong Kong Polytechnic University, Hong Kong, China. ${ }^{6}$ These authors contributed equally: Di Wu, Haotian Zheng. ${ }^{\varpi}$-mail: qli@fudan.edu.cn; xiang-dong.li@polyu.edu.hk; shxwang@tsinghua.edu.cn 

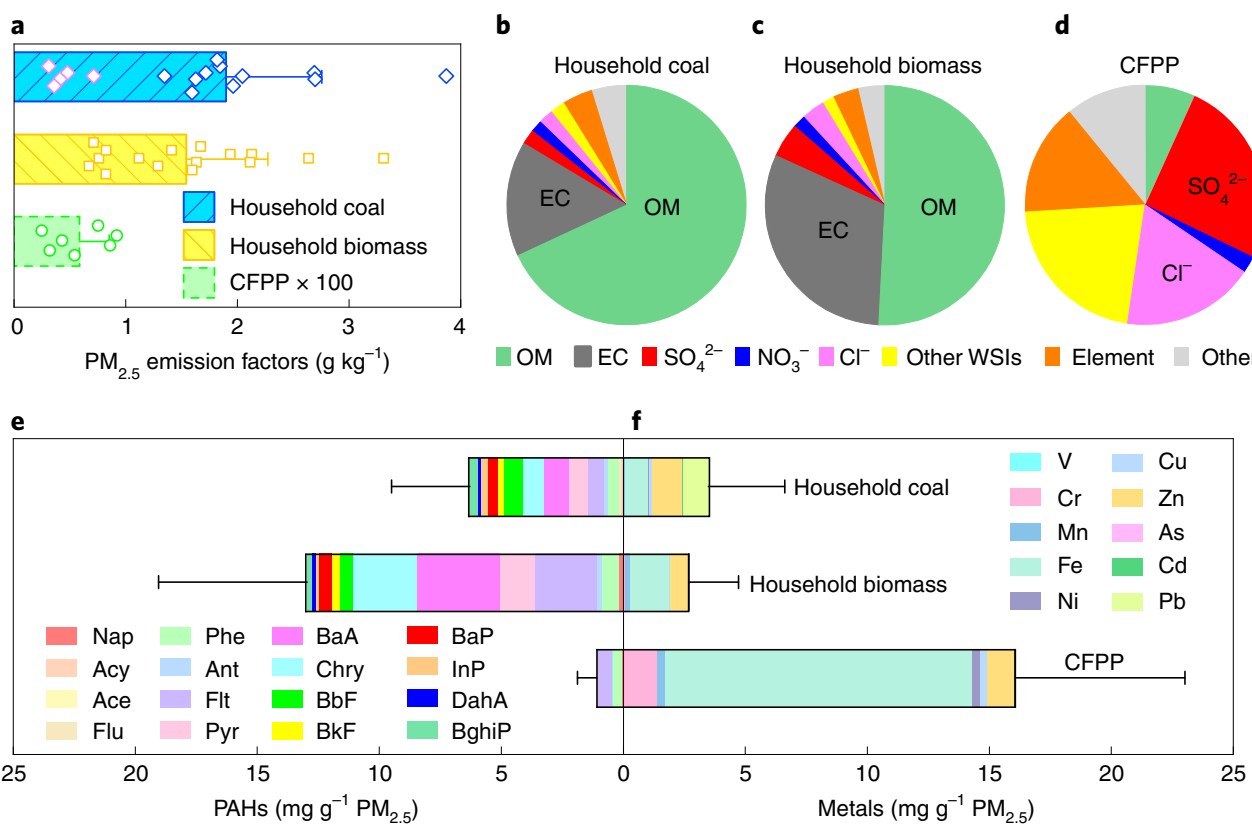

b

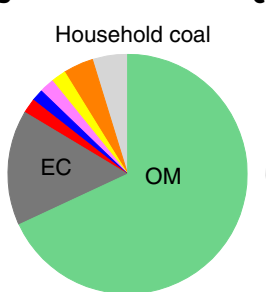

C

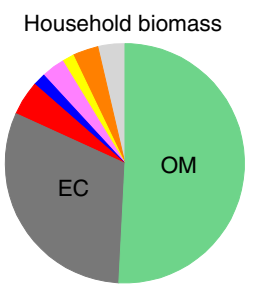

d

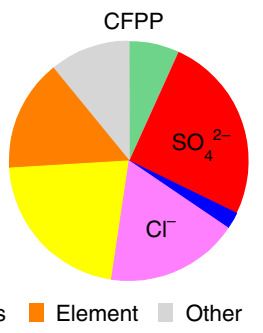

$\mathrm{OM} \square \mathrm{EC} \square \mathrm{SO}_{4}{ }^{2-} \square \mathrm{NO}_{3}{ }^{-} \square \mathrm{Cl}^{-} \square$ Other WSIs $\square$ Element $\square$ Other f

Fig. 1 | Real-world $\mathbf{P M}_{2.5}$ emission profiles. a, $\mathrm{PM}_{2.5}$ EFs for the residential sector and CFPPs. The coloured points (yellow squares and green circles) are the measured EFs of individual samples, while the red and blue diamond patterns represent anthracite and bituminous coals, respectively. Data are presented as mean values \pm s.d. b-d, Relative mass distributions of $\mathrm{PM}_{2.5}$ emitted from household coal combustion (b), household biomass combustion (c) and CFPP (d). Organic matter (OM) is estimated as organic carbon (OC) $\times 1.2$; the elements include Al, Ca, K, Mg, Na, P, S, Si, Li, Be, Sc, Ti, V, Cr, Mn, Fe, Co, Ni, Cu, $\mathrm{Zn}, \mathrm{Ga}, \mathrm{Ge}, \mathrm{As}, \mathrm{Se}, \mathrm{Rb}, \mathrm{Sr}, \mathrm{Mo}, \mathrm{Pd}, \mathrm{Ag}, \mathrm{Cd}, \mathrm{Sn}, \mathrm{Sb}, \mathrm{Cs}, \mathrm{Ba}, \mathrm{Pt}, \mathrm{Au}, \mathrm{Ti}$ and Pb; and other WSIs include $\mathrm{Li}^{+}, \mathrm{Na}^{+}, \mathrm{NH}_{4}{ }^{+}, \mathrm{K}^{+}, \mathrm{Mg}^{2+}, \mathrm{Ca}^{2+}, \mathrm{F}^{-}, \mathrm{Br}^{-}$and PO${ }^{3-} . \mathrm{EC}^{2}$ elemental carbon. e,f, The mass concentrations of 16 PAHs per unit mass of $\mathrm{PM}_{2.5}$ samples (e) and 10 toxic metals (f) (that is, $\mathrm{V}$, Cr, Mn, Fe, Ni, Cu, Zn, As, $\mathrm{Cd}$ and $\mathrm{Pb}$ ) per unit mass of $\mathrm{PM}_{2.5}$ samples; data are presented as mean values \pm s.d. See Supplementary Table 2 for the PAHs and their abbreviations.

emission concentration at CFPP stacks nationwide), which had installed in over 95\% of China's power capacity by 2017 ( refs. ${ }^{7,27}$ ). The large discrepancy of $\mathrm{PM}_{2.5}$ EFs between the residential and power plant sectors is consistent with previous studies ${ }^{20,24,25}$. The relative distributions of chemical constituents of $\mathrm{PM}_{2.5}$ demonstrate large differences between residential stoves and CFPPs (Fig. 1b-d). Owing to the low combustion efficiency of residential solid fuel burning, carbonaceous species including organic matter and elemental carbon form the main components of residential $\mathrm{PM}_{25}$, comprising $83.1 \pm 6.5 \%$ of the total $\mathrm{PM}_{25}$ emitted from household stoves. The mass fractions of organic matter and elemental carbon contained in $\mathrm{PM}_{2.5}$ are 37.4-85.6\% and 7.8-44.0\% for household burning emissions, respectively, while inorganic constituents (that is, sulfate, nitrate, chloride and elements) are minor fractions of household $\mathrm{PM}_{2.5}$. In contrast, CFPP-emitted $\mathrm{PM}_{2.5}$ is dominated by inorganic species (that is, water-soluble ions (WSIs) and elements), which account for $82.3 \pm 10.9 \%$ of the total $\mathrm{PM}_{2.5}$ mass concentration, while carbonaceous species contribute only $6.7 \pm 4.1 \%$ to the total $\mathrm{PM}_{2.5}$. Sulfate and chloride are the dominant ions, responsible for $25.4 \pm 11.9 \%$ and $17.9 \pm 5.7 \%$ of the total CFPPs $\mathrm{PM}_{2.5}$, respectively. The observed compositions of $\mathrm{PM}_{2.5}$ from residential combustion and CFPPs are both consistent with those reported in previous studies (Supplementary Table 1). Carbonaceous materials dominate $\mathrm{PM}_{2.5}$ emitted from the residential combustion, while inorganic species are the main component of CFPPs $\mathrm{PM}_{2.5}$. Among these chemical species, only minor fractions of these carbonaceous materials and inorganic species (for example, polycyclic aromatic hydrocarbons (PAHs) and metals) are often targeted and regarded as key contributors to negative health effects. ${ }^{28,29}$

There are large discrepancies in the emissions of 16 $\mathrm{PM}_{2.5}$-bound PAHs between the residential sector and CFPPs equipped with advanced emission controls (Fig. 1e). The EFs of 16 PAHs of per unit mass of $\mathrm{PM}_{2.5}$ emitted from burning coal $\left(6.29 \pm 3.20 \mathrm{mg} \mathrm{g}^{-1}\right)$ and biomass $\left(13.0 \pm 6.1 \mathrm{mgg}^{-1}\right)$ in domestic stoves are much higher than those of the PAHs emitted from CFPPs $\left(1.08 \pm 0.79 \mathrm{mg} \mathrm{g}^{-1}\right)$. Compared with the $\mathrm{PM}_{2.5}$-bound PAHs from CFPPs, the residential sector-emitted PAHs are much more abundant in high-toxicity-potency PAHs (TEF greater than or equal to 0.1 ), together contributing $39.0-45.9 \%$ of the total PAHs (Supplementary Fig. 1a). In contrast, the EFs of ten priority toxic metals (that is, $\mathrm{V}, \mathrm{Cr}, \mathrm{Mn}, \mathrm{Fe}, \mathrm{Ni}, \mathrm{Cu}, \mathrm{Zn}, \mathrm{As}, \mathrm{Cd}$ and $\mathrm{Pb}$ ) per unit mass of $\mathrm{PM}_{2.5}$ emitted from CFPPs $\left(16.0 \pm 7.0 \mathrm{mg} \mathrm{g}^{-1}\right)$ are greater than those of metals emitted from burning coal $\left(3.49 \pm 3.12 \mathrm{mg} \mathrm{g}^{-1}\right)$ and biomass $\left(2.75 \pm 2.04 \mathrm{mg} \mathrm{g}^{-1}\right)$ in domestic stoves (Fig. 1f). The relative proportions of these metals in CFPP-emitted $\mathrm{PM}_{2.5}$ exceeds that in $\mathrm{PM}_{2.5}$ emitted from residential solid fuel combustion by roughly 4.6-5.8-fold with a large discrepancy (Supplementary Fig. 1b), mainly due to the different metal contents of the solid fuels ${ }^{30}$. However, the fuel-based EFs of the targeted metals from the residential sector are more than 40 times higher than those from CFPPs, while the fuel-based EFs of the 16 PAHs are more than three orders of magnitude higher for the residential solid fuel combustion than for CFPPs.

Unequal toxicity of emitted $\mathbf{P M}_{2.5}$. Figure $2 \mathrm{a}$, b shows the corresponding benzo(a)pyrene ( $\mathrm{BaP}$ )-equivalent carcinogenic potency $\left(\mathrm{BaP}_{\mathrm{eq}}\right)$ values of the total $16 \mathrm{PAHs}$ and the Cr-equivalent carcinogenic potency $\left(\mathrm{Cr}_{\mathrm{eq}}\right)$ values of the ten toxic metals, respectively (Supplementary Tables 2 and 3). The EFs of $\mathrm{BaP}_{\text {eq }}$ per unit mass $\mathrm{PM}_{2.5}$ emitted from household coal $\left(0.78 \pm 0.44 \mathrm{mg} \mathrm{g}^{-1}\right)$ and biomass $\left(1.12 \pm 0.53 \mathrm{mg} \mathrm{g}^{-1}\right)$ combustion are significantly $\left(P=2 \times 10^{-6}\right)$ higher than those emitted from CFPPs $\left(1.41 \pm 0.88 \mu \mathrm{gg}^{-1}\right)$, exceeding the latter values by roughly 553- and 794-fold, respectively. High-toxic potency species, including $\mathrm{BaP}$, benzo(a)anthracene and dibenzo(a,h)anthracene, dominated the $\mathrm{BaP}_{\text {eq }}$ content in the residential sector, accounting for $83.5-87.9 \%$ of the total $\mathrm{BaP}_{\mathrm{eq}}$. In the CFPP-emitted $\mathrm{PM}_{2.5}$ samples, the top three species (that is, fluoranthene, phenanthrene and anthracene) contributing to 
a

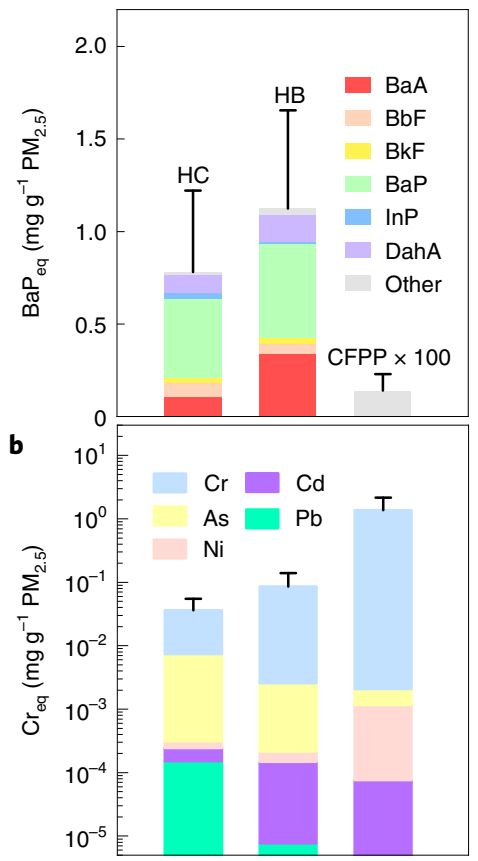

c

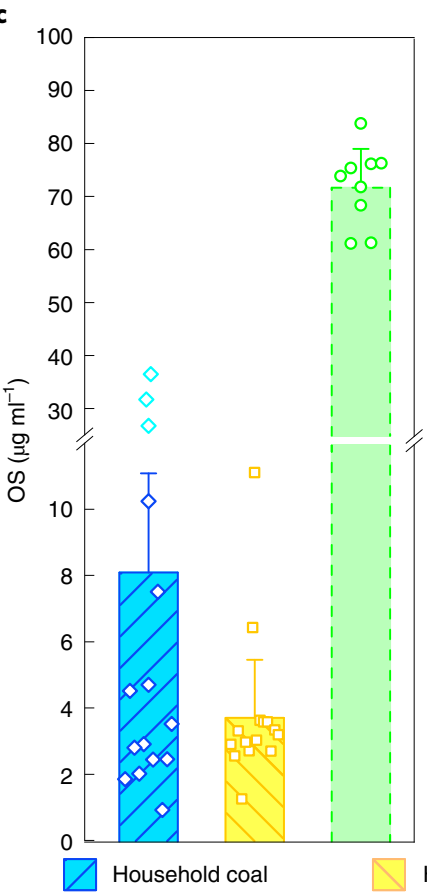

d

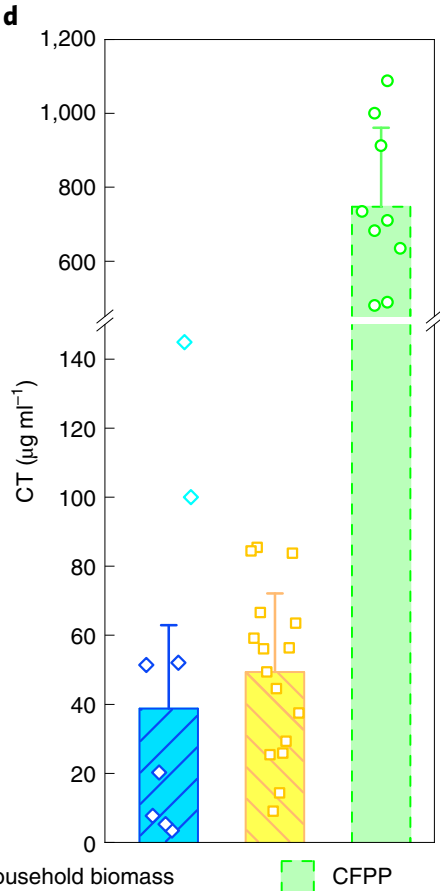

Fig. 2 | Unequal toxicity of primary $\mathbf{P M}_{2.5}$ emitted from solid fuel combustion. $\mathbf{a}, \mathbf{b}$, Toxic equivalent carcinogenic potency of $\mathrm{PAHs}$ (BaP $\mathrm{eq}$ ) (a) and toxic metals $\left(\mathrm{Cr}_{\mathrm{eq}}\right)$ (b) per unit mass of $\mathrm{PM}_{2.5}$ samples in household coal (HC), household biomass (HB) combustion and CFPPs. 'Other' includes Nap, Ace, Acy, Flu, Phe, Ant, Flt, Pyr, Chry and BghiP (with toxic equivalence factors $<0.1$ ). $\mathbf{c}, \mathbf{d}, \mathrm{EC}_{1.5}(\mathbf{c})$ and IC 20 (d) of PM 2.5 samples emitted from the residential sector and CFPPs; their values decrease with increasing toxicity. OS, oxidative stress and CT, cytotoxicity. The coloured points correspond to the toxicity of individual samples, while the cyan and blue diamond patterns represent anthracite and bituminous coals, respectively. Data are presented as mean values \pm s.d.

$\mathrm{BaP}_{\text {eq }}$, together making up roughly $95.0 \%$ of the total $\mathrm{BaP}_{\text {eq }}$, are less toxic species. Owing to the significantly $\left(P=1 \times 10^{-5}\right)$ higher EFs of primary PM and PM-bound high-toxic potency PAHs from the residential sector, the fuel-based $\mathrm{EFs}$ of $\mathrm{BaP}_{\mathrm{eq}}$ for the residential sectors are approximately five orders of magnitude higher than those for CFPPs. These results indicate that exposure to household combustion-generated $\mathrm{PM}_{2.5}$ has much higher carcinogenic potency. The EFs of $\mathrm{Cr}_{\text {eq }}$ per unit mass $\mathrm{PM}_{2.5}$ emitted from CFPPs $\left(1.36 \pm 0.78 \mathrm{mg} \mathrm{g}^{-1}\right)$ are one order of magnitude higher than those emitted from the residential sector. In contrast, the fuel-based total $\mathrm{Cr}_{\text {eq }}$ values for the residential sector are 7 to 16 times higher per unit mass of solid fuel than those for CFPPs. These estimated $\mathrm{BaP}_{\mathrm{eq}}$ and $\mathrm{Cr}_{\text {eq }}$ values may have additional uncertainties because the interactions among individual species have been ignored. Owing to the large variation in chemical components, especially hazardous species between residential and CFPP-emitted $\mathrm{PM}_{2.5}$, the chemical-specific toxicity of $\mathrm{PM}_{2.5}$ emitted from residential stoves and CFPPs needs to be examined and quantified.

A significant inequality is exhibited in toxic potencies of primary $\mathrm{PM}_{2.5}$ emitted from residential sectors and CFPPs, including the oxidative stress $\left(P=1 \times 10^{-15}\right)$ and cytotoxicity $\left(P=6 \times 10^{-16}\right)$ (Fig. 2c,d). The endpoints of triggered reactive oxidative species (ROS) generation and cell viability in human lung cell lines (A549) are reported as $\mathrm{EC}_{1.5}$ (the effect concentration resulting in a 1.5-fold induction of intracellular ROS generation) and $\mathrm{IC}_{20}$ (the inhibitory concentration resulting in $20 \%$ of cell viability decline) values. The $\mathrm{PM}_{2.5}$ toxicity increased with decreasing $\mathrm{EC}_{1.5}$ and $\mathrm{IC}_{20}$ values. The $\mathrm{PM}_{2.5} \mathrm{EC}_{1.5}$ values for household coal and biomass combustion are $8.1 \pm 3.0$ and $3.7 \pm 2.3 \mu \mathrm{g} \mathrm{ml}^{-1}$, respectively, which are nearly one order of magnitude higher than that for $\mathrm{PM}_{2.5}$ emitted from CFPPs $\left(72.0 \pm 7.3 \mu \mathrm{g} \mathrm{ml}^{-1}\right)$. The $\mathrm{PM}_{2.5} \mathrm{IC}_{20}$ values for household coal and biomass combustion are $38.7 \pm 24.1$ and $49.4 \pm 22.7 \mu \mathrm{g} \mathrm{ml}^{-1}$, respectively, which are roughly 19- and 15-fold greater than that of CFPP $\mathrm{PM}_{2.5}\left(748 \pm 213 \mu \mathrm{g} \mathrm{ml}^{-1}\right)$. The result from the estimation of cellular toxicity indicates that primary $\mathrm{PM}_{2.5}$ emitted from household solid fuel combustion is much more toxic than that emitted from CFPPs.

The much higher toxic potencies of $\mathrm{PM}_{25}$ emitted from household combustion are substantially attributed to the $\mathrm{BaP}_{\mathrm{eq}}$ of the 16 PAHs contained in $\mathrm{PM}_{2.5}$, the correlation coefficients between the $\mathrm{PM}_{2.5}$ toxic potencies (oxidative stress and cytotoxicity) and the $\mathrm{BaP}_{\mathrm{eq}}$ are $92 \%$ and $75 \%$, respectively (Supplementary Fig. 2). These high correlations suggest that the 16 PAHs or associated organic chemicals play a vital role in $\mathrm{PM}_{2.5}$-associated unequal toxicity. PAHs, as the refractory fraction of organic carbon, are mainly formed and released during incomplete solid fuel combustion processes $^{31}$. The relationship between $\mathrm{BaP}_{\text {eq }}$ and the modified incomplete combustion efficiency (MICE), defined as 1-MCE (modified combustion efficiency) to characterize combustion completion, suggests that toxic PAH emission is mainly determined by the combustion process. The $\mathrm{BaP}_{\text {eq }}$ values for household stoves are significantly correlated $\left(P=1.3 \times 10^{-5}\right)$ with the MICE and accounts for $90 \%$ of the variation in the $\mathrm{BaP}_{\text {eq }}$ (Supplementary Fig. 3). The corresponding linear fitting yields the equation as: $\mathrm{BaP}_{\mathrm{eq}}=16.04 \times$ MICE0.33 , where the MICE is an independent variable for $\mathrm{BaP}_{\text {eq. }}$. Highly incomplete combustion occurs when coal and biomass are burned in domestic stoves (MICE values ranging between 3.7\% and 10.6\%). The average MICE value for household stoves $(6.7 \pm 2.3 \%)$ is significantly higher $\left(P=4 \times 10^{-7}\right)$ than that for CFPP $(0.03 \pm 0.02 \%)$, indicating that the residential combustion process is substantially incomplete compared to the industrial boiler combustion ${ }^{32}$.

The fractional contribution of targeted PAHs accounts for 64-97\% to residential $\mathrm{PM}_{2.5}$-induced intracellular ROS (Supplementary Fig. 4), which is estimated from the concentration addition reference model ${ }^{29}$. The result further identifies that $\mathrm{BaP}_{\mathrm{eq}}$ originating from an incomplete combustion processes dominates the toxic potency of residential $\mathrm{PM}_{2.5}$. Most PAHs from household combustion, especially high-ring aromatics, exist in a $\mathrm{PM}_{2.5}$-bound state and thus trigger a greater toxic potency. In contrast, the selected metals, which are 
Solid fuel consumption (Mtce)

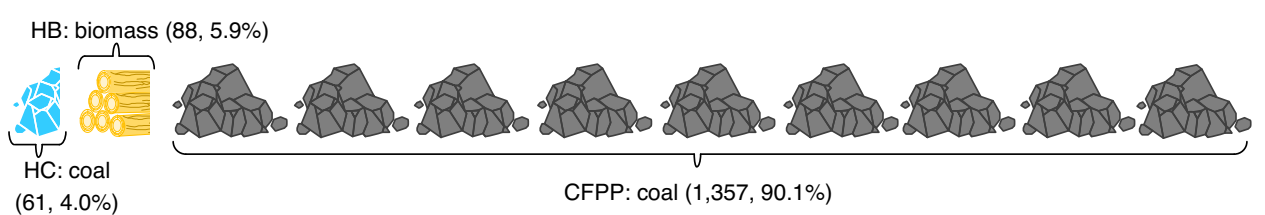

b
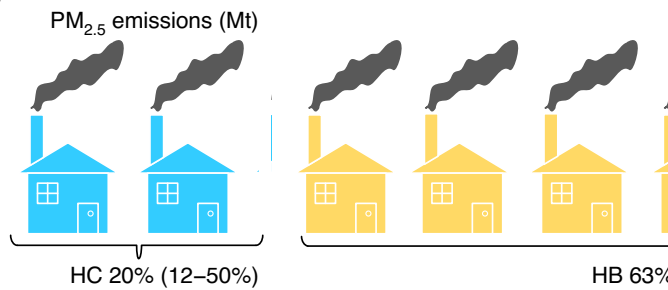

HB $63 \%(19-75 \%)$
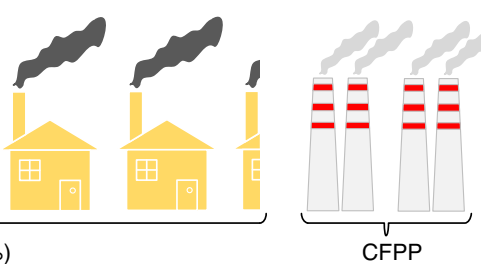

$17 \%(10-36 \%)$

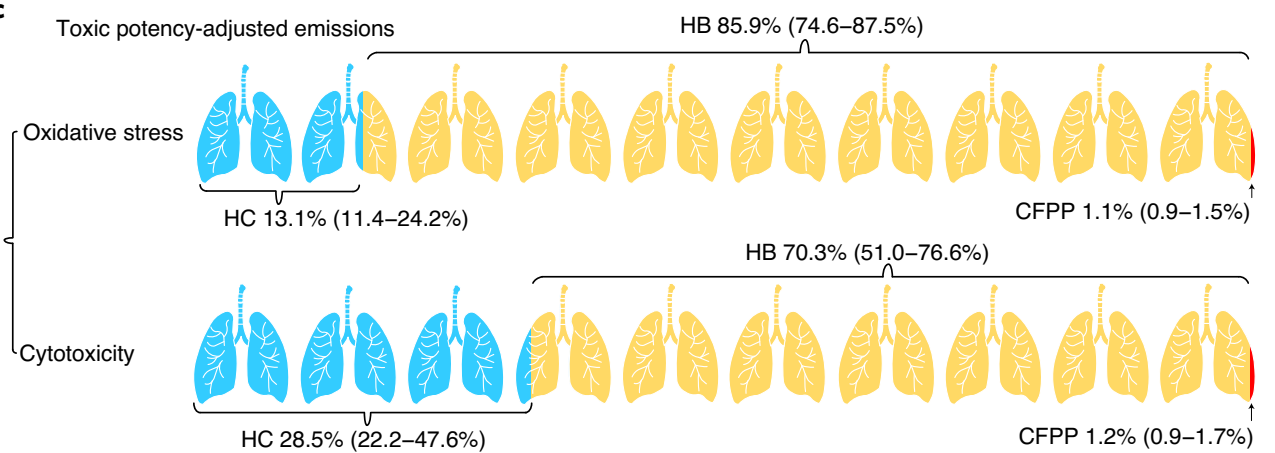

Fig. 3 | Fuel consumption, $\mathbf{P M}_{\mathbf{2 . 5}}$ emissions and $\mathbf{P M}_{\mathbf{2 . 5}}$-related toxic potency-adjusted emissions. a-c, Solid fuel consumption (a), $\mathrm{PM}{ }_{2.5}$ emissions (b) and $\mathrm{PM}_{2.5}$-related toxic potency-adjusted emissions (c) conbributed from the residential sector and CFPPs. Blue and orange represent PM ${ }_{2.5}$ emissions and their related toxic potency-adjusted emissions from household coal (HC) and biomass (HB) combustions in 2017 , respectively, while red represents $\mathrm{PM}_{2.5}$-related toxic potency-adjusted emissions from CFPPs in 2017. Data of $\mathrm{PM}_{2.5}$ emissions and their related toxic potency-adjusted emissions are presented as mean values $\pm 95 \%$ confidence intervals (in brackets).

known as key toxic components, dominate the overall contributions to CFPP $\mathrm{PM}_{2.5}$-induced ROS generation $(81 \pm 7 \%)$. Although previous studies suggested that metals and PAHs made similar contributions to atmospheric PM-induced toxicity ${ }^{29,33-35}$, their relative importance vary widely in toxicities of PMs from solid fuel combustion in the residential sector and CFPPs. The much higher toxicity of primary $\mathrm{PM}_{25}$ emitted from the residential solid fuel combustion can be mainly attributed to the incomplete combustion released PAHs, while the toxicity of CFPP-emitted $\mathrm{PM}_{2.5}$ is dominated by toxic metals. The observed $\mathrm{PM}_{2.5}$-related toxic potencies can reflect toxicities of $\mathrm{PM}_{2.5}$ originating from these two source categories.

$\mathbf{P M}_{2.5}$-related toxic potency-adjusted emissions. The solid fuel consumption, $\mathrm{PM}_{2.5}$ emission and $\mathrm{PM}_{2.5}$-related toxicity- (including estimations of oxidative stress and cytotoxicity) -adjusted emissions contributed by the residential sector and CFPPs in 2017 in mainland China are demonstrated in Fig. 3. The total amount of consumed solid fuels, including residential coal and biomass as well as the primary $\mathrm{PM}_{2.5}$ generated from the household combustion and CFPPs, were obtained from the ABaCAS emission inventory developed at Tsinghua University ${ }^{17,36}$. Among the two sectors, the residential sector consumes only $9.9 \%$ of the total consumed solid fuel, among them $4.0 \%$ (61 million-ton coal equivalents (Mtce)) and 5.9\% (88 Mtce) are household coal and biomass, respectively, while CFPPs account for most of the solid fuel consumption at $90.1 \%(1,357 \mathrm{Mtce})$ (Fig. 3a). The household combustion-generated $\mathrm{PM}_{2.5}(82.8 \%, 64.0-89.4 \%)$ dominates the overall $\mathrm{PM}_{2.5}$ emitted from the solid fuel combustion for direct energy usage in the two sectors, while the proportion of CFPP-emitted $\mathrm{PM}_{2.5}$ is relatively low (17.2\%, 10.4-35.8\%) (Fig. 3b). Furthermore, the national $\mathrm{PM}_{2.5}$-related toxicity-adjusted emissions (Supplementary Note 7) from the two sectors are dominated by household-emitted $\mathrm{PM}_{2.5}$, with relative contributions of 98.9\% (98.5-99.1\%) and 98.8\% (98.4-99.1\%) for oxidative stress and cytotoxicity, respectively. The contribution of CFPP-emitted $\mathrm{PM}_{2.5}$ constitutes a small fraction of the nationwide $\mathrm{PM}_{2.5}$ toxicity-adjusted emissions, with percentages of $1.1 \%(0.9-1.5 \%)$ and $1.2 \%(0.9-1.6 \%)$ for oxidative stress and cytotoxicity, respectively; these contributions can be considered negligible compared to those from the residential sector (Fig. 3c).

The annual variations in solid fuel consumption, $\mathrm{PM}_{2.5}$ emission and $\mathrm{PM}_{2.5}$-related toxicity-adjusted emissions for the residential sector and CFPPs from 2005 to 2017 are illustrated in Supplementary Fig. 5. For the residential sector, coal consumption fluctuated slightly over the 12 years, and biomass consumption decreased rapidly (by 62\%) due to the rapid development of urbanization in China, while coal consumption by CFPPs increased by $81 \%$ during this period. However, owing to the high MICE and the lack of air pollution control devices, the small fraction of solid fuels burned in household stoves accounts for $76-83 \%$ of the overall $\mathrm{PM}_{2.5}$ emissions from national solid fuel combustion. Since Chinese CFPPs have to meet the strengthening emission standards of local governments, the overall $\mathrm{PM}_{2.5}$ emissions from CFPPs have gradually decreased especially after the implementation of ULE standards in 2014 , even as relative coal consumption has increased. The total contributions of CFPP-emitted $\mathrm{PM}_{2.5}$ decreased steadily from 2005 

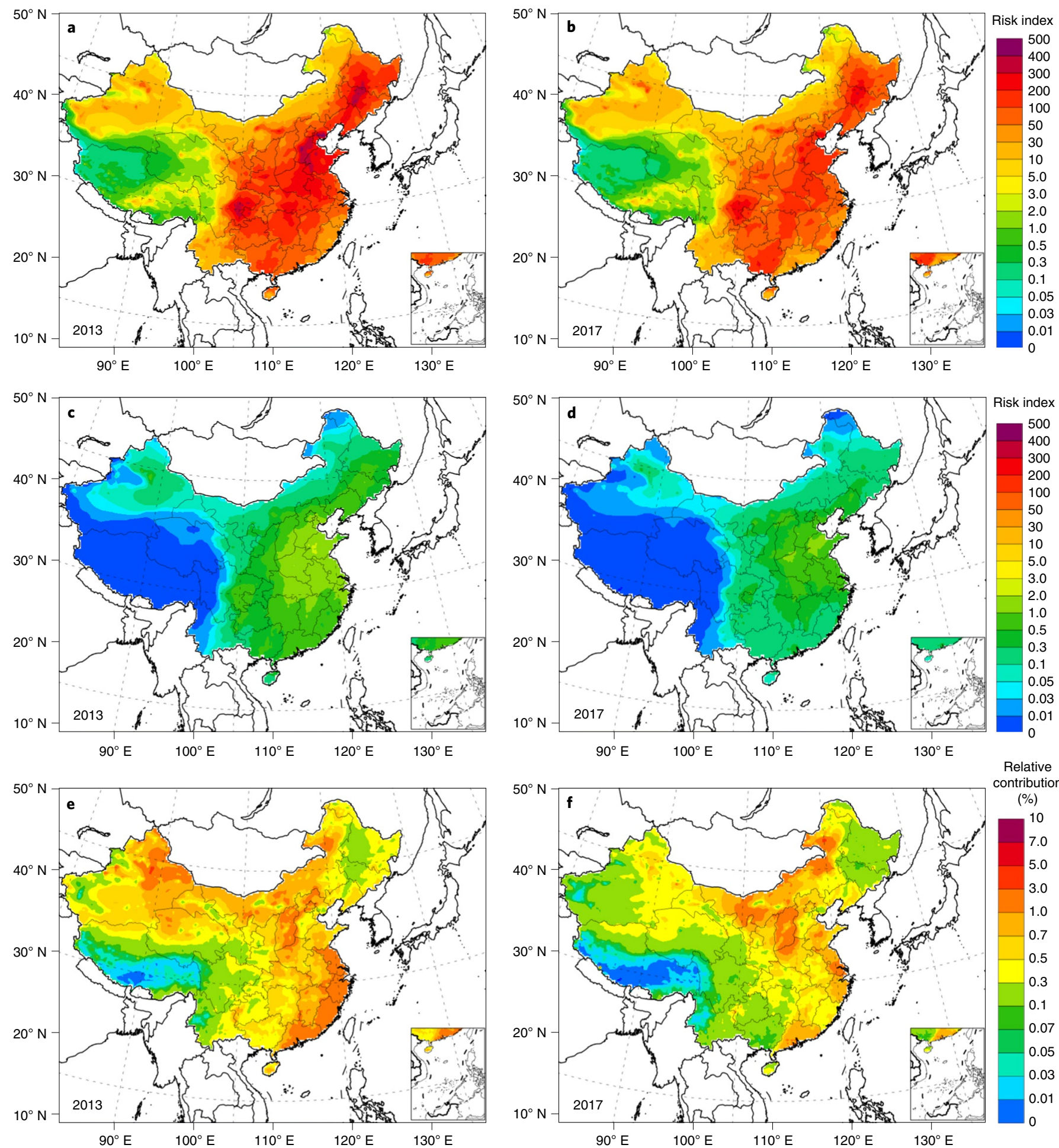

Fig. 4 | Spatial distribution of primary PM $_{2.5}$-related oxidative stress adjusted exposure. a-d, Spatial distribution for the risk index of TPAE $E_{O S}$ originating from the residential sector in 2013 (a) and 2017 (b), and CFPPs in 2013 (c) and 2017 (d). e,f, Relative contribution of CFPP-emitted PM 2.5 to the overall TPAE $_{O S}$ across the nation in 2013 (e) and 2017 (f).

to 2017, during which the relative contributions of CFPPs to oxidative stress- and cytotoxicity-adjusted emissions decreased by $35.5 \%$ and $34.6 \%$, respectively. The decrease rate of $\mathrm{PM}_{2.5}$-related toxic potencies-adjusted emissions from CFPPs is substantially larger than that from the residential sector. Consequently, the relative contributions from household-emitted $\mathrm{PM}_{2.5}$ to the national $\mathrm{PM}_{2.5}$-induced ROS- and cytotoxicity-adjusted emissions have both gradually increased.
Although residential solid fuel consumption with high MICE values decreases annually during this period, the exposure risk burden of emitted $\mathrm{PM}_{2.5}$ remains steady and is dominated by the contribution from solid fuel combustion, owing to their unequal toxicities. The toxic potency-adjusted emissions contributed from the residential combustion far exceeds the contribution from CFPPs in mainland China. After ULE standards were introduced for CFPPs in 2014, the relative contribution from CFPPs has decreased rapidly 
and could now be considered negligible. Furthermore, regional disparities in solid fuel consumption by the two sectors can lead to temporal and spatial variations in PM emissions and the associated toxic potency-adjusted exposure to PM across the nation.

Household burning dominates toxic potency-adjusted PM exposure. $\mathrm{PM}_{2.5}$ concentration and sector contributions were simulated using the WRF-CMAQ model. The annual average $\mathrm{PM}_{2.5}$ concentrations originating from the residential sector are much higher than those from CFPPs in mainland China in 2013 and 2017 (Supplementary Figs. 6 and 7). The population-weighted exposure (PWE) to $\mathrm{PM}_{2.5}$ is dominated by the residential sector, which accounted for $90.0 \%(87.3-93.5 \%)$ and $92.4 \%(90.5-93.0 \%)$ of the total PWE in 2013 and 2017, respectively (Supplementary Table 4). TPAE is used as a metric for the risk index of the toxic potency-adjusted exposure to $\mathrm{PM}_{2.5}$, including estimations of oxidative stress- and cytotoxicity-adjusted exposure to $\mathrm{PM}_{2.5}\left(\mathrm{TPAE}_{\mathrm{OS}}\right.$ and $\mathrm{TPAE}_{\mathrm{CT}}$ ). Figure 4 demonstrates the spatial distribution of $\mathrm{TPAE}_{\mathrm{OS}}$ for the residential sector and CFPPs in 2013 and 2017. Since 2014, China has implemented the strictest ULE standards for CFPPs. Substantially higher intensities of $\mathrm{TPAE}_{\mathrm{OS}}$ for the residential sector than that for CFPPs are observed across mainland China in both years (Fig. 4a,b). Much higher levels of residential TPAE ${ }_{\mathrm{OS}}$ are observed on the Northeast China Plain, North China Plain and the Sichuan Basin, especially in central Jilin, southern Hebei and eastern Sichuan, since these areas are major agricultural regions with lower urbanization rates and higher population densities than other regions ${ }^{30}$. The variation in $\mathrm{TPAE}_{\mathrm{OS}}$ between residential coal and biomass (Supplementary Fig. 8) is mainly attributed to the geographical disparity and imbalance in regional economic development, which has led to regional discrepancies in solid fuel consumption, and the associated $\mathrm{PM}_{2.5}$ emissions and their toxicities (Supplementary Table 5).

The population-weighted $\mathrm{TPAE}_{\mathrm{OS}}$ originating from the residential sector predominates the total population-weighted TPAE $_{\mathrm{OS}}$ across the nation throughout years, which had increased from $99.4 \%(99.1-99.5 \%)$ to $99.5 \%(99.3-99.6 \%)$ over this period (Supplementary Table 6), although the absolute population-weighted $\mathrm{TPAE}_{\mathrm{OS}}$ for the residential sectors had decreased by $32 \%$. The population-weighted $\mathrm{TPAE}_{\mathrm{OS}}$ originating from CFPPs decreased by $52 \%$ during this period. The areas of high $\mathrm{TPAE}_{\mathrm{OS}}$ from CFPPs are distributed in northern and eastern China (Fig. 4c,d), especially in the Shandong and Henan Provinces, where the concentrations of CFPP stacks are the highest in the nation ${ }^{7}$. With the implementation of the strictest emission standards for CFPPs in 2014, the relative contribution of CFPPs to the overall $\mathrm{TPAE}_{\mathrm{OS}}$ in the two sectors has decreased nationwide in 5 years (Fig. 4e,f), and the highest reductions occurred in the Yangtze River Delta region. The tendency of the $\mathrm{TPAE}_{\mathrm{CT}}$ is highly consistent with that for $\mathrm{TPAE}_{\mathrm{OS}}$ across mainland China (Supplementary Figs. 9 and 10).

The relative contribution of CFPP-emitted $\mathrm{PM}_{2.5}$ accounted for approximately $0.5 \%$ of the total population-weighted TPAE in 2017. The results indicate that national mitigation strategies, mainly focusing on CFPPs, may not mitigate the toxic potency-adjusted exposure risks from residential energy use. The residential sector, a more important anthropogenic source of population exposure risks than previously thought, has been overlooked throughout the years. Emissions from the residential energy use (that is, heating and cooking) have the largest impact on premature mortality on a global scale, especially in China and India ${ }^{4}$. A nationwide study also indicates that coal consumption in the residential sector resulted in 40 times higher premature deaths than in the power and industrial sectors $^{37}$. However, the results of the increased toxicity of residential combustion have not been reported in population-based studies. The missing link to epidemiological findings may increase the uncertainties of the current estimation of aerosol toxicities for solid fuel combustion. Consequently, population-based cohort studies on solid fuel combustion are expected to integrate with different toxicological data to comprehensively estimate the population health risks in the future.

Controls on PM emissions from the residential sector (mass emission along with toxic potency) are urgently needed to relieve the exposure risk from inhalable aerosols, especially in less-developed regions of China. Since residential energy use are prevalent in developing countries (that is, India, Indonesia, Nepal, Ethiopia, Nigeria and Kenya and so on $)^{4,11,14,38}$ and even highly developed regions (that is, Finland and Netherlands $)^{39,40}$, residents living in these countries may have higher toxic potency-adjusted exposure risk from residential emission than previously thought. Local and national governments urgently need to take action to control substantial PM emissions from incomplete combustion of residential solid fuels.

Since this study focuses mainly on primary PM emissions and PM-related toxicity, the result may underestimate the adverse effects from solid fuel combustion emitted PM without considering the secondary PM transformed from gaseous pollutants from residential solid fuel burning ${ }^{41}$. In addition, PM-related toxicity based on the intracellular estimation provides a screen of short-term exposure and does not reflect the long-term exposure effect, which may limit the comprehensive understanding of PM-associated toxic effects. The estimation of toxic constituent-specific contribution to the overall PM-related toxicity based on the concentration addition model is likely to overlook the interacting effect of each individual toxic compound in the mixture, particularly among metals, which might influence the prediction accuracy. The limited field measurements did not include all the biomass fuel and coal types of usage in the residential sector, as well as the CFPP equipped with various air pollution control devices across the nation, and this leads to additional uncertainties in this study (Supplementary Note 9). The observed toxic potencies of residential and CFPP $\mathrm{PM}_{2.5}$ from the current study may have uncertainties owing to the limited field samples. More efforts are needed to investigate and explain the toxicological properties for residential and CFPP $\mathrm{PM}_{2.5}$, as well as other source-specific $\mathrm{PM}_{2.5}$ across different areas. Future work also needs to integrate secondary aerosols and their related toxicity into the corresponding toxic potency-adjusted PM exposure. Furthermore, broader health relevant biological endpoints (that is, immunotoxic and genotoxic endpoints) based on both in vitro and in vivo tests should be used and linked to human epidemiological data to explain the PM-related toxic potency, thus aiming to comprehensively estimate the health risks of solid fuel combustion. CFPPs are important in highly developed regions including the USA, while residential solid fuel consumption is not the leading pollution source in these regions ${ }^{4,11}$. The results observed in this study may not be applicable to regions that do not show wide usage of solid fuels in the residential sector. Additionally, the health benefits and the cost-benefit evaluation are not discussed in this study. Further studies are expected to address these important issues.

\section{Conclusions}

This study proposes toxic potency-adjusted control of air pollution and reveals the unequal toxicities between $\mathrm{PM}_{2.5}$ emitted from solid fuel combustion. The much lower combustion efficiency of the residential combustion results in much higher levels of PAHs in residential energy use-generated $\mathrm{PM}_{2.5}$ and thus leads to much higher $\mathrm{PM}_{2.5}$-related toxicities, including estimations from oxidative stress and cytotoxicity. When integrating the $\mathrm{PM}_{2.5}$-related toxic potencywith the population-weighted $\mathrm{PM}_{2.5}$ exposure, residential $\mathrm{PM}_{2.5}$ dominates (99.4-99.6\%) the overall population-weighted toxic potency-adjusted exposure to $\mathrm{PM}_{2.5}$, especially in economically underdeveloped regions. In contrast, CFPPs constitute a minor fraction of the overall population-weighted toxic potency-adjusted exposure to $\mathrm{PM}_{2.5}$ under the implementation of 
the strictest ULE standards, whose contribution can be negligible nationwide. Considering EFs and national energy consumption in 2017, the residential sector consumed only one-tenth of solid fuels, but contributed 218-fold (153-248) higher population-weighted toxic potency-adjusted $\mathrm{PM}_{2.5}$ exposure, when compared to CFPPs in mainland China. The obtained results indicate that the exposure risks caused by household solid fuel use are much higher than those from CFPPs when taking $\mathrm{PM}_{2.5}$-related toxic potency into consideration. Therefore, the exposure risk from residential energy use warrants more attention. Further air pollution control policies need to focus on incomplete combustion sources, particularly household solid fuel combustion in less-developed regions. As a feasible countermeasure, the promotion of combustion efficiency may mitigate hazardous constituent emissions and achieve health benefits. Furthermore, it may be more effective to control air pollution by integrating $\mathrm{PM}_{2.5}$-related toxic potency into regional $\mathrm{PM}_{2.5}$ standards.

\section{Methods}

Field sampling. There were 1,510 CFPPs in northern and eastern China in 2017, accounting for $60 \%$ of total capacity across the nation ${ }^{7}$. Owing to severe air pollution problem, the ULE retrofits have performed most frequently in north and east regions ${ }^{27}$. The compliance rate with the ULE standards for CFPPs in northern and eastern regions were $70 \%$ and $93 \%$ by 2017 , respectively ${ }^{7}$. To investigate the emission characteristics and toxic potencies of PM emitted from CFPPs under the ULE standards, seven typical units located in northern and eastern China were selected in the current study. The sampling information for the CFPPs is detailed in Supplementary Note 1, Supplementary Fig. 11 and Supplementary Table 7. The air pollution control measures taken in CFPPs are detailed in Supplementary Note 3 and Supplementary Tables 8 and 9. Bituminous coal (Supplementary Note 4 and Supplementary Table 10) was burned in these tested boilers during the field measurements. $\mathrm{PM}_{2.5}$ samples were collected from the stacks (Supplementary Fig. 11) with quartz and Teflon filters according to US EPA methods 17 and 201A (Supplementary Note 5 and Supplementary Fig. 12). The selected units were operated at a stable generating load at over $75 \%$ of their capacity during each test. Three successful tests were performed at each tested location in the selected units. The field sampling method and the quality control methods for the industrial emissions are also detailed in our previous study ${ }^{42}$.

The field sampling of household solid fuel combustion was carried out in typical households in three villages in northern and southwestern China on the basis of their commonly used fuel types (that is, bituminous coal, anthracite coal, wood and crop residue) and stove types (that is, iron stoves, brick stoves and three-stone stoves), which include the main types of solid fuel and stove across the whole nation (Supplementary Note 2, Supplementary Table 10 and Supplementary Figs. 13-15) $)^{5,26}$. Several widely used solid fuels, including three types of bituminous coal, three types of anthracite coal, typical local wood and four crop residues (that is, rice, wheat, corn and bean residue), were burned during the field study (Supplementary Table 10). Six commonly used household stoves, including two household heating stoves and four household cooking stoves (that is, one three-stone stove, one new iron stove, one typical brick stove and one old steel stove), were selected for the real-world experiments. All the stoves except the three-stone stove were equipped with chimneys. Photos of the tested stoves are presented in the Supplementary Figs. 14 and 15. The coal samples were weighed to $5.0 \mathrm{~kg}$ for each test of the iron stove, whereas the wood and crop residue samples for the three-stone, iron and brick cooking stoves were balanced at 2.0 and $1.0 \mathrm{~kg}$, respectively. A schematic diagram of the sampling system is shown in the Supplementary Fig. 16. For the household cooking and heating experiments, the tested stoves remained in their usual locations in kitchens, while the chimneys were replaced with shorter pieces to hold their outlets under an exhaust hood equipped with an electric blower as a constant-volume system to dilute the emitted flue gases. The diluted flue gases then passed through a vent pipe. The flow rate (fixed at $1,320 \mathrm{~m}^{3} \mathrm{~h}^{-1}$ ) was measured by using an airflow capture hood (Kanomax model 6710). The concentrations of gaseous species $\left(\mathrm{CO}, \mathrm{CO}_{2}, \mathrm{NO}_{\mathrm{x}}\right.$ and $\left.\mathrm{SO}_{2}\right)$ were monitored via a flue gas analyser (Testo 350). Homemade samplers and $\mathrm{PM}_{2.5}$ cyclones (URG 2000-30EH) were used to collect total suspended particulate and $\mathrm{PM}_{2.5}$ samples. The PM samples were collected on quartz or Teflon filters (Whatman) for the different analyses. Two parallel samples were collected on both quartz and Teflon filters. Three successful measurements were performed for each solid fuel and stove combination. The air pollution control measures taken in the residential sector is detailed in Supplementary Note 3 and Supplementary Table 8.

Analysis approach. The EFs of $\mathrm{PM}_{2.5}$ per unit of burned fuel were determined with the direct mass weight method for household combustion and direct EF calculation method on the basis of total flue gas flow and coal combustion rate for CFPPs (Supplementary Note 7). The MICE was defined as $1-\mathrm{MCE}, \mathrm{MCE}=\Delta\left(\mathrm{CO}_{2}\right)$ /
$\left(\Delta\left(\mathrm{CO}_{2}\right)+\Delta(\mathrm{CO})\right)$, where $\Delta\left(\mathrm{CO}_{2}\right)$ and $\Delta(\mathrm{CO})$ indicate the molar amounts of $\mathrm{CO}_{2}$ and $\mathrm{CO}$ observed from field measurements with the corresponding background levels subtracted, respectively. The MICE was used to quantify the incomplete combustion efficiencies of the tested combustion processes.

The PM samples collected on the quartz fibre filters were used to determine the carbonaceous fractions and 16 US EPA priority PAHs, while the PM samples collected on the Teflon filters were used to measure the concentrations of WSIs and elemental species (Supplementary Note 6), using the same formula as that used in the previous study ${ }^{43}$. The conversion factor from organic carbon to organic matter varied widely for different fuels. The value 1.2, commonly used for source-specific PM samples ${ }^{20}$, was used as the conversion factor in this study. On the basis of toxicity equivalency factors (TEFs), namely the ratios of the toxicities of individual PAHs to the toxicity of $\mathrm{BaP}$, the EFs of the $\mathrm{PM}_{2.5}$-bound $\mathrm{BaP}_{\text {eq }}$ were calculated to estimate the cancer risk from the 16 PAHs contained in $\mathrm{PM}_{2.5}$ samples. The TEFs of individual PAHs were taken from a previous study ${ }^{44}$. Sixteen US EPA priority PAHs, their abbreviations and TEFs are listed in the Supplementary Table 2. The EFs of $\mathrm{PM}_{2.5}$-bound $\mathrm{Cr}_{\text {eq }}$ were examined to evaluate the carcinogenic risk from ten selected metals contained in the $\mathrm{PM}_{2.5}$ samples. The TEFs of the identified metals were estimated on the basis of carcinogenic risk parameters cited from the US EPA, as listed in the Supplementary Table 3.

A549 cell lines were used to investigate $\mathrm{PM}_{2.5}$-related toxic potency. $\mathrm{PM}_{2.5}$ samples were extracted with methanol, and the solvent was dried with purified nitrogen. A $2^{\prime}, 7^{\prime}$-dichlorofluorescein diacetate (DCFH-DA) assay and a 3-(4,5-dimethylthiazol-2-yl)-2,5-diphenylte-trazolium bromide (MTT) assay were used to determine the intracellular ROS generation and cell viability caused by exposure to $\mathrm{PM}_{2.5}$ extracts, respectively. The optical density was determined at $570 \mathrm{~nm}$, and the fluorescence intensity was detected at $488 / 525 \mathrm{~nm}$ via a microplate reader (Varioskan LUX, Thermo Scientific). The details of the procedures can be found in previous studies ${ }^{43,45}$

Development of the emission inventory. The emission inventory for China during 2005-2017 was developed on the basis of a bottom-up method and the emission of power plants and key industrial processes were quantified by a unit-based approach, the same as our previous studies ${ }^{46,47}$. For domestic coal and biomass combustion, we considered rural and urban areas separately, although both included combustion for heating, cooking and hot water production. For coal combustion, in urban areas, we considered district heating, coal boilers and coal stoves, while in rural areas, we considered only coal stoves. For biomass combustion, we considered biomass stoves and biogas stoves. The activity data, that is energy consumption for domestic combustion, were collected from an array of sources, including statistical yearbooks and surveys. For power plants, the emission inventory was developed with a unit-based method. For 2017, the PM emissions from 3,193 power plants were quantified; a detailed method for the calculation of the unit-based emission inventory is presented in a previous study ${ }^{46}$.

Estimation of toxic potency-adjusted $\mathbf{P M}_{2.5}$ exposure. The WRF-CMAQ model was used to simulate the concentrations of ambient $\mathrm{PM}_{2.5}$. The simulation period included the entire year for both 2013 and 2017. Four scenarios (baseline scenario, no household coal (NoHC) scenario, no household biomass (NoHB) scenario and no electricity (NoELE) scenario) were designed to estimate the ambient $\mathrm{PM}_{25}$ concentration originating from the residential sector and CFPPs. The baseline scenario was simulated with the WRF-CMAQ model and the updated ABaCAS emission inventory. The NoHC, NoHB and NoELE scenarios were simulated on the basis of the emission inventories without primary PM emissions from household coal, household biomass or CFPP from the baseline scenario, respectively. The difference between the baseline scenario and the sum of the $\mathrm{NoHC}$ and NoHB scenarios was used as the estimation of the contribution of the residential sector to the ambient $\mathrm{PM}_{2.5}$ concentrations, while the difference between the baseline scenario and the NoELE scenario was used as the estimation of the contribution of CFPPs to the ambient $\mathrm{PM}_{2.5}$ concentrations. The model performance was evaluated by comparing the simulated parameters with on-the-ground observations (Supplementary Note 8 and Supplementary Table 11). The comparisons of source apportionment results of ambient $\mathrm{PM}_{2.5}$ from the two sectors in China with other studies are shown in Supplementary Table 12. Aiming to evaluate the source apportionment in this study, two extra simulations for each scenario and year to constrain the bounds on the basis of the uncertainties of the emission inventory and WRF-CMAQ model have been conducted. The uncertainties of the $\mathrm{PM}_{2.5}$ emissions from CFPPs, household coal burning and household biomass burning were assessed by 10,000 Monte Carlo runs on the basis of the probability distribution of the activity data, the efficiency of the control measures and the share of each end-of-pipe control technology (Supplementary Note 9 and Supplementary Table 13). The PWE was defined as:

$$
\mathrm{PWE}=\frac{1}{P} \sum_{i} P_{i} \times C_{i},
$$

where $P$ is the total population, and $P_{i}$ and $C_{i}$ are the population and ambient $\mathrm{PM}_{2.5}$ concentrations in each geographic unit $(i)$, respectively. $\mathrm{PM}_{2.5}$-related toxic 
potency, including estimations of oxidative stress (OS) and cytotoxicity (CT), were used as metrics for the TPAE. The risk index for TPAE $\mathrm{OS}_{\mathrm{OS}}$ and TPAE $\mathrm{CT}_{\mathrm{CT}}$ were estimated as TPAE $\mathrm{OS}_{i}=C_{i} \times \mathrm{OS}_{i}$ and $\mathrm{TPAE}_{\mathrm{CT}}=C_{i} \times \mathrm{CT}_{i}$, where $\mathrm{OS}_{i}$ and $\mathrm{CT}_{i}$ are the toxic equivalent values of $\mathrm{PM}_{25}$-related oxidative stress and cytotoxicity in each geographic unit $(i)$, respectively; which were estimated on the basis of the toxic units of $\mathrm{PM}_{25}$-related oxidative stress and cytotoxicity (Supplementary Note 7 and Supplementary Table 5). The population-weighted TPAE $\mathrm{OS}_{\mathrm{O}}$ and $\mathrm{TPAE}_{\mathrm{CT}}$ were estimated as $\mathrm{PWE}_{i} \times \mathrm{OS}_{i}$ and $\mathrm{PWE}_{i} \times \mathrm{CT}_{i}$ (Supplementary Table 6). The uncertainty of the toxic potency-adjusted emissions includes both the uncertainties of the emission inventory and the toxicity test results, while the uncertainty of the toxic potency-adjusted exposure to $\mathrm{PM}_{25}$ includes the uncertainties of the source apportionment results and the toxicity test results.

\section{Data availability}

All data needed to evaluate the conclusions are present in the paper and/or the Supplementary Information. Source data are provided with this paper.

\section{Code availability}

WRF and CMAQ are open-source models. The source codes are available on their release websites (https://github.com/NCAR/WRFV3/releases and https://github. com/USEPA/CMAQ/releases).

Received: 25 January 2021; Accepted: 3 November 2021; Published online: 6 January 2022

\section{References}

1. Liu, J. et al. Air pollutant emissions from Chinese households: a major and underappreciated ambient pollution source. Proc. Natl Acad. Sci. USA 113, 7756-7761 (2016).

2. Zhang, J. J. \& Smith, K. R. Household air pollution from coal and biomass fuels in China: measurements, health impacts, and interventions. Environ. Health Perspect. 115, 848-855 (2007).

3. Huang, R. J. et al. High secondary aerosol contribution to particulate pollution during haze events in China. Nature 514, 218-222 (2014).

4. Lelieveld, J., Evans, J. S., Fnais, M., Giannadaki, D. \& Pozzer, A. The contribution of outdoor air pollution sources to premature mortality on a global scale. Nature 525, 367-371 (2015).

5. Tao, S. et al. Quantifying the rural residential energy transition in China from 1992 to 2012 through a representative national survey. Nat. Energy 3, 567-573 (2018).

6. Oberschelp, C., Pfister, S., Raptis, C. E. \& Hellweg, S. Global emission hotspots of coal power generation. Nat. Sustain. 2, 113-121 (2019).

7. Tang, L. et al. Substantial emission reductions from Chinese power plants after the introduction of ultra-low emissions standards. Nat. Energy 4 , 929-938 (2019).

8. Zhang, Q. et al. Drivers of improved $\mathrm{PM}_{2.5}$ air quality in China from 2013 to 2017. Proc. Natl Acad. Sci. USA 116, $24463-24469$ (2019).

9. Tong, D. et al. Targeted emission reductions from global super-polluting power plant units. Nat. Sustain. 1, 59-68 (2018).

10. Klimont, Z. et al. Global anthropogenic emissions of particulate matter including black carbon. Atmos. Chem. Phys. 17, 8681-8723 (2017).

11. Weagle, C. L. et al. Global sources of fine particulate matter: interpretation of $\mathrm{PM}_{2.5}$ chemical composition observed by SPARTAN using a global chemical transport model. Environ. Sci. Technol. 52, 11670-11681 (2018).

12. Lin, C. et al. Extreme air pollution from residential solid fuel burning. Nat. Sustain. 1, 512-517 (2018).

13. Yun, X. et al. Residential solid fuel emissions contribute significantly to air pollution and associated health impacts in China. Sci. Adv. 6, eaba7621 (2020).

14. Conibear, L., Butt, E. W., Knote, C., Arnold, S. R. \& Spracklen, D. V. Residential energy use emissions dominate health impacts from exposure to ambient particulate matter in India. Nat. Commun. 9, 617 (2018).

15. Zhao, H. et al. Inequality of household consumption and air pollution-related deaths in China. Nat. Commun. 10, 4337 (2019).

16. Zheng, B. et al. Trends in China's anthropogenic emissions since 2010 as the consequence of clean air actions. Atmos. Chem. Phys. 18, 14095-14111 (2018).

17. Zhao, B. et al. Change in household fuels dominates the decrease in PM2.5 exposure and premature mortality in China in 2005-2015. Proc. Natl Acad. Sci. USA 115, 12401-12406 (2018).

18. Daellenbach, K. R. et al. Sources of particulate-matter air pollution and its oxidative potential in Europe. Nature 587, 414-419 (2020).

19. $\mathrm{Li}, \mathrm{Q}$. et al. Improving the energy efficiency of stoves to reduce pollutant emissions from household solid fuel combustion in China. Environ. Sci. Techol. Lett. 3, 369-374 (2016).

20. Zhang, Y. et al. Characteristics of particulate carbon emissions from real-world Chinese coal combustion. Environ. Sci. Technol. 42, 5068-5073 (2008).
21. Shen, G. et al. Field measurement of emission factors of PM, EC, OC, parent, nitro-, and oxy- polycyclic aromatic hydrocarbons for residential briquette, coal cake, and wood in rural Shanxi, China. Environ. Sci. Technol. 47, 2998-3005 (2013)

22. Wu, B. et al. Effects of wet flue gas desulfurization and wet electrostatic precipitators on emission characteristics of particulate matter and its ionic compositions from four $300 \mathrm{MW}$ level ultralow coal-fired power plants. Environ. Sci. Technol. 52, 14015-14026 (2018).

23. Li, X., Kan, H. \& Jin, L. Air pollution: a global problem needs local fixes. Nature 570, 437-439 (2019).

24. $\mathrm{Li}, \mathrm{Q}$. et al. Influences of coal size, volatile matter content, and additive on primary particulate matter emissions from household stove combustion. Fuel 182, 780-787 (2016).

25. Jayarathne, T. et al. Nepal Ambient Monitoring and Source Testing Experiment (NAMaSTE): emissions of particulate matter from wood- and dung-fueled cooking fires, garbage and crop residue burning, brick kilns, and other sources. Atmos. Chem. Phys. 18, 2259-2286 (2018).

26. Liu, X. et al. Spatially resolved emission factors to reduce uncertainties in air pollutant emission estimates from the residential sector. Environ. Sci. Technol. 55, 4483-4493 (2021).

27. Liu, X. et al. Updated hourly emissions factors for Chinese power plants showing the impact of widespread ultralow emissions technology deployment. Environ. Sci. Technol. 53, 2570-2578 (2019).

28. Shiraiwa, M., Selzle, K. \& Poschl, U. Hazardous components and health effects of atmospheric aerosol particles: reactive oxygen species, soot, polycyclic aromatic compounds and allergenic proteins. Free Radic. Res. 46, 927-939 (2012)

29. Jin, L. et al. Contributions of city-specific fine particulate matter (PM2.5) to differential in vitro oxidative stress and toxicity implications between Beijing and Guangzhou of China. Environ. Sci. Technol. 53, 2881-2891 (2019).

30. $\mathrm{Li}, \mathrm{Q}$. et al. Impacts of household coal and biomass combustion on indoor and ambient air quality in China: current status and implication. Sci. Total Environ. 576, 347-361 (2017).

31. Dat, N.-D. \& Chang, M. B. Review on characteristics of PAHs in atmosphere, anthropogenic sources and control technologies. Sci. Total Environ. 609, 682-693 (2017)

32. Baumgartner, J. et al. Highway proximity and black carbon from cookstoves as a risk factor for higher blood pressure in rural China. Proc. Natl Acad. Sci. USA 111, 13229-13234 (2014).

33. Osornio-Vargas, A. R. et al. Proinflammatory and cytotoxic effects of Mexico City air pollution particulate matter in vitro are dependent on particle size and composition. Environ. Health Perspect. 111, 1289-1293 (2003).

34. $\mathrm{Hu}, \mathrm{S}$. et al. Redox activity and chemical speciation of size fractioned PM in the communities of the Los Angeles-Long Beach Harbor. Atmos. Chem. Phys. 8, 6439-6451 (2008)

35. Pardo, M., Shafer, M. M., Rudich, A., Schauer, J. J. \& Rudich, Y. Single exposure to near roadway particulate matter leads to confined inflammatory and defense responses: possible role of metals. Environ. Sci. Technol. 49, 8777-8785 (2015).

36. Leung, D. M. et al. Wintertime particulate matter decrease buffered by unfavorable chemical processes despite emissions reductions in China. Geophys. Res. Lett. 47, e2020GL087721 (2020).

37. Yun, X. et al. Coal is dirty, but where it is burned especially matters. Environ. Sci. Technol. 55, 7316-7326 (2021).

38. Lacey, F. G., Henze, D. K., Lee, C. J., van Donkelaar, A. \& Martin, R. V. Transient climate and ambient health impacts due to national solid fuel cookstove emissions. Proc. Natl Acad. Sci. USA 114, 1269-1274 (2017).

39. Karvosenoja, N. et al. Evaluation of the emissions and uncertainties of $\mathrm{PM}_{2.5}$ originated from vehicular traffic and domestic wood combustion in Finland. Boreal Environ. Res. 13, 465-474 (2008).

40. Denier van der Gon, H. A. C. et al. Particulate emissions from residential wood combustion in Europe - revised estimates and an evaluation. Atmos. Chem. Phys. 15, 6503-6519 (2015).

41. Zhou, S. et al. Multiphase reactivity of polycyclic aromatic hydrocarbons is driven by phase separation and diffusion limitations. Proc. Natl Acad. Sci. USA 116, 11658-11663 (2019).

42. Ding, X. et al. Unexpectedly increased particle emissions from the steel industry determined by wet/semidry/dry flue gas desulfurization technologies. Environ. Sci. Technol. 53, 10361-10370 (2019).

43. Wu, D. et al. Primary particulate matter emitted from heavy fuel and diesel oil combustion in a typical container ship: characteristics and toxicity. Environ. Sci. Technol. 52, 12943-12951 (2018).

44. Delistraty, D. Toxic equivalency factor approach for risk assessment of polycyclic aromatic hydrocarbons. Toxicol. Environ. Chem. 64, 81-108 (1997)

45. Wu, D., Zhang, F., Lou, W., Li, D. \& Chen, J. Chemical characterization and toxicity assessment of fine particulate matters emitted from the combustion of petrol and diesel fuels. Sci. Total Environ. 605-606, 172-179 (2017).

46. Zheng, $H$. et al. Development of a unit-based industrial emission inventory in the Beijing-Tianjin-Hebei region and resulting improvement in air quality modeling. Atmos. Chem. Phys. 19, 3447-3462 (2019). 
47. Zheng, H. et al. Transition in source contributions of $\mathrm{PM}_{2.5}$ exposure and associated premature mortality in China during 2005-2015. Environ. Int. 132, 105111-105124 (2019)

\section{Acknowledgements}

We thank K. R. Smith from UC Berkeley for his valuable contributions to designing the framework of this study, and we deeply mourn his passing. We thank R. Huang from the Institute of Earth Environment of CAS for providing insightful discussions and Z. Guo from Fudan University for supporting the experimental analysis. This work was funded by the National Natural Science Foundation of China (grant nos. 91743202, 21625701, T2122006, 21876028, 92043302 and 42007393) and the Research Grants Council of Hong Kong (grant nos. 15210618 and 25210420). S. Wang was also supported by the Tencent Foundation through the XPLORER PRIZE and the Samsung Advanced Institute of Technology.

\section{Author contributions}

Q.L., S.W. and X.L. conceived and designed the experiments. Q.L. and D.W. performed the experiments. D.W., H.Z. and L.J. analysed the data. R.L., B.Z., X.D., Y.H., J.J. and J.C. contributed materials/analysis tools. D.W., H.Z. and Q.L. wrote the paper withcontributions from the other authors.

\section{Competing interests}

The authors declare no competing interests.

\section{Additional information}

Supplementary information The online version contains supplementary material available at https://doi.org/10.1038/s41560-021-00951-1.

Correspondence and requests for materials should be addressed to Qing Li, Xiangdong Li or Shuxiao Wang.

Peer review information Nature Energy thanks Lucas Henneman, Nguyen Thi Kim Oanh and Yueming (Lucy) Qiu for their contribution to the peer review of this work Reprints and permissions information is available at www.nature.com/reprints. Publisher's note Springer Nature remains neutral with regard to jurisdictional claims in published maps and institutional affiliations.

(c) (i) Open Access This article is licensed under a Creative Commons Attribution 4.0 International License, which permits use, sharing, adaptation, distribution and reproduction in any medium or format, as long as you give appropriate credit to the original author(s) and the source, provide a link to the Creative Commons license, and indicate if changes were made. The images or other third party material in this article are included in the article's Creative Commons license, unless indicated otherwise in a credit line to the material. If material is not included in the article's Creative Commons license and your intended use is not permitted by statutory regulation or exceeds the permitted use, you will need to obtain permission directly from the copyright holder. To view a copy of this license, visit http://creativecommons. org/licenses/by/4.0/.

(C) The Author(s) 2022 